\title{
INOVAÇÃO NA EDUCAÇÃO FÍSICA ESCOLAR: DESAFIANDO A PREVISÍVEL IMUTABILIDADE DIDÁTICO-PEDAGÓGICA ${ }^{1}$
}

\author{
Daniel Teixeira Maldonado \\ Instituto Federal de Educação, Ciência e Tecnologia de São Paulo, São Paulo, São Paulo, Brasil. \\ Pollyane de Barros Albuquerque Vieira \\ Universidade São Judas Tadeu, São Paulo, São Paulo, Brasil. \\ Luiz Sanches Neto \\ Universidade Federal do Ceará, Fortaleza, Ceará, Brasil. \\ Elisabete dos Santos Freire \\ Universidade São Judas Tadeu, São Paulo, São Paulo, Brasil.
}

\begin{abstract}
Resumo
Com o objetivo de compreender as características das práticas pedagógicas inovadoras, analisamos os artigos científicos sobre inovação no cotidiano escolar da Educação Física (EF), publicados em periódicos dos estratos A1 a B5 do WebQualis 2014. Identificamos 161 artigos que analisavam a inovação na EF escolar, sendo que uma relevante parte desta produção é divulgada em periódicos situados em revistas classificadas nos estratos B4 e B5. A diversificação das temáticas apresentadas, a sistematização do currículo e a seleção de variadas estratégias de ensino foram as principais formas de inovação identificadas. Concluímos que há um crescimento no número de publicações que evidenciam a existência de práticas pedagógicas que rompem com a tradição que tem marcado a EF.
\end{abstract}

Palavras-chave: Educação Física. Escola. Inovação pedagógica. Cotidiano escolar.

\section{Introdução}

A organização didática da EF na escola brasileira esteve voltada, em diferentes sistemas educacionais, para o ensino das destrezas esportivas, com a intenção de valorizar o esporte de alto rendimento e diagnosticar "alunos atletas". Esta perspectiva foi adotada a partir do incentivo das políticas públicas para o setor, baseada na ideia de que sua missão principal seria trabalhar para que as equipes esportivas obtivessem êxito em competições nacionais e internacionais, configurando uma prática pedagógica técnica e tradicional nas aulas de EF (SILVA; BRACHT, 2012).

No cotidiano escolar, ainda encontramos práticas pedagógicas em EF que podem ser consideradas tradicionais. Entretanto, já é possível observar a existência de docentes que planejam e viabilizam práticas inovadoras, por vezes orientadas pela produção do movimento renovador da EF brasileira (BRACHT, 2011). São consideradas inovadoras as práticas peda-

\footnotetext{
${ }^{1} \mathrm{O}$ presente trabalho não contou com apoio financeiro de nenhuma natureza para a sua realização.
} 
gógicas que têm se concretizado na EF, fundamentadas na perspectiva de que esse componente curricular possui um conhecimento relevante socialmente e que é dever da escola fazer com que as novas gerações se apropriem dos conteúdos relacionados com as manifestações da cultura corporal de movimento. Trata-se de vivenciar as diferentes práticas corporais que compõe essa cultura, além dos conhecimentos de ordem conceitual que o docente de EF pode tematizar com os seus alunos sobre essas mesmas práticas (BRACHT, 2011).

Portanto, para ser considerado inovador, o docente de EF precisa organizar as suas ações didáticas, problematizando conhecimentos biológicos, sociológicos, filosóficos, econômicos e políticos referentes à cultura corporal de movimento, além de relacionar a sua prática pedagógica com o projeto político pedagógico da escola, deixando de lado o ensino pautado no paradigma da aptidão física (FENSTERSEIFER; SILVA, 2011).

Essas características que percorrem a prática pedagógica dos professores de EF inovadores surgem por conta das mudanças que ocorrem constantemente na sociedade contemporânea. Betti (2011, p. 24) menciona que "a tradição da EF precisa ser renovada pelos sentidos, valores e práticas que emergem da dinâmica sociocultural". O autor descreve como exemplo as práticas corporais radicais e de aventura; as práticas corporais alternativas; a associação do jogo, do esporte e da dança com as tecnologias do virtual; e a valorização das práticas corporais relacionadas com a ginástica, cujo objetivo é enfatizar um determinado padrão de beleza. Nesse sentido, os próprios alunos acabam trazendo esses temas para dentro da sala de aula, gerando uma oportunidade para que o professor estimule debates e reflexões nas aulas de EF inovadoras.

Para Bracht (2011), a implementação de práticas pedagógicas inovadoras permite superar o monopólio do esporte, possibilitando aos discentes conhecer e vivenciar diferentes danças, jogos populares, ginásticas, esportes radicais, lutas, dentre outras práticas corporais. $\mathrm{O}$ método de ensino construído por professores inovadores valoriza a gestão democrática da aula, solicitando uma participação mais efetiva dos alunos sobre o que poderá ser aprendido.

Consideramos, ainda, que uma ação didática inovadora da EF necessita estar comprometida com os princípios da equidade, direitos, justiça social e cidadania, ao tematizar as práticas corporais, questionando as condições de classe, etnia, gênero, níveis de habilidade, local de moradia, histórias pessoais e religião dos estudantes. Nessa perspectiva, os docentes devem estar engajados na luta pela transformação social, valorizando experiências de reflexão crítica sobre as diferentes práticas corporais, como propõe Neira (2010).

Ao desafiar o senso comum, que aponta uma "previsível" imutabilidade na Educação Física Escolar (EFE), desde que esse componente curricular é ensinado nas escolas, Correia (2014) argumenta que já é possível observar a implementação de novas perspectivas didáticopedagógicas nas aulas do componente, já que existe uma participação crescente dos professores de EF em congressos, seminários e simpósios, cuja contribuição tem mostrado um grande interesse em expor suas práticas pedagógicas como formas de protagonismo e inovação curricular, conquistando a legitimidade da EF como componente curricular.

Ao analisar dois periódicos científicos da área, Neira (2012) identificou contribuições da academia para este processo de inovação. Esta contribuição torna-se mais evidente em Maldonado, Silva e Miranda (2014), que realizaram um estudo de estado da arte sobre o cotidiano da EFE e analisaram 697 artigos de 63 periódicos da Educação e da EF. Os autores verificaram que $17,5 \%$ da produção científica sobre a EF na escola esteve relacionada com a inovação pedagógica e essa produção de conhecimento aumenta significativamente com o passar dos anos, demonstrando indícios de que a prática pedagógica desse componente curricular vem sendo transformada ao longo das décadas.

Acreditamos que a análise das características dessa produção pode contribuir para uma melhor compreensão sobre como a inovação pedagógica tem se concretizado no cotidiano escolar. Partindo dessa premissa, realizamos o presente estudo com o objetivo de compreen- 
der as características das práticas pedagógicas inovadoras implementadas por docentes de EF que trabalham nas escolas brasileiras. Ele é parte de um projeto de pesquisa que teve por objetivo analisar a produção do conhecimento sobre o cotidiano da EFE.

\section{Método da Pesquisa}

Para atingir o objetivo proposto neste estudo, optamos por realizar uma investigação sobre o estado da arte de pesquisas que mostraram a inovação pedagógica nas aulas de EF no cotidiano escolar. Esse tipo de pesquisa permite identificar como a produção acadêmica sobre um determinado objeto de estudo tem sido realizada, sendo possível compreender as escolhas metodológicas adotadas pelos pesquisadores (ROMANOWSKY; ENS, 2006), bem como as diferentes perspectivas que fundamentam os estudos. Também permite identificar os principais resultados obtidos e, por conseguinte, as lacunas que podem orientar a realização de novas pesquisas, contribuindo com a organização, análise e constituição de um corpo teórico de uma área de conhecimento.

Estabelecemos como recorte temporal o período entre 1980 e 2015. Assim, foram incluídos na análise artigos que analisaram a inovação pedagógica no cotidiano escolar durante as aulas de EF, publicados em periódicos nacionais da área da EF e da Educação, presentes nos estratos de A1 a B5 do WebQualis de 2014, para a área 21 da CAPES. Foram excluídos da pesquisa ensaios, resenhas, artigos de revisão de literatura ou de opinião, e outros textos que não tinham o cotidiano escolar brasileiro como foco. Foram excluídos, ainda, artigos nos quais se analisava a opinião de professores que atuam no Ensino Superior sobre a temática proposta e as análises de documentos que não foram criados pelo corpo técnico-docente de escolas, por exemplo, as propostas curriculares, plano diretor e currículos institucionalizados.

Foram consultados 43 periódicos científicos, sendo 20 deles da área da Educação (Quadro 1) e 23 específicos da EF (Quadro 2). Para selecioná-los, o escopo de cada revista foi analisado para verificar a intencionalidade dela em contribuir com a divulgação do conhecimento sobre as Ciências Humanas e Pedagógicas, sobre a escola ou sobre a EF escolar. Em cada periódico foram selecionados os estudos que apresentavam, no título ou nas palavraschave, os seguintes descritores: educação física; escola; currículo; e cotidiano. A intenção foi realizar uma busca abrangente para ampliar a possibilidade de encontrar artigos em que a inovação pedagógica estivesse presente.

Quadro 1 - Revistas Brasileiras de Educação utilizadas na pesquisa

\begin{tabular}{|ll|}
\hline Atos de Pesquisa em Educação & Rev. Brasileira de Educação Especial \\
Cadernos de Formação UFPEL & Rev. Brasileira de Estudos Pedagógicos \\
Cadernos de Pesquisa: pensamento educacional & Rev. Teoria e Prática da Educação \\
Rev. Contemporânea de Educação & Rev. Educação em Questão \\
Rev. Educação Pública & Rev. Educação Especial \\
Educação e Sociedade & Rev. Interdisciplinar de Filosofia e Educação \\
Educação em Revista & Rev. Eletrônica de Educação \\
Interface & Rev. Formação Docente \\
Rev. Espaço do Currículo & Rev. Psicologia Escolar e Educacional \\
Instrumento: revista de estudo e pesquisa em Edu- & Rev. Brasileira de Educação de Jovens e Adultos \\
cação & \\
\hline
\end{tabular}

Fonte: Elaborado pelo autor, 2017. 
Quadro 2 - Revistas Brasileiras de Educação Física utilizadas na pesquisa

Arquivos em Movimento
Biomotriz
Cadernos de Formação - RBCE
Coleção Pesquisa em EF
Conexões
EF em Revista
Motriz
Motricidade
Motrivivência
Movimento
Pensar a Prática
Pulsar

Rev. Brasileira de Atividade Física e Saúde
Rev. Brasileira de Ciências do Esporte
Rev. Brasileira de Ciência e Movimento
Rev. Brasileira de EF e Esporte
Rev. Brasileira de Futebol e Futsal
Rev. Brasileira de Prescrição e Fisiologia do Exer-
cício
Rev. de EF da UEM
Rev. Kinesis
Rev. Mackenzie de EF e Esporte
Rev. Mineira de EF
Licere
Licere

Fonte: Elaborado pelo autor, 2017.

Após o levantamento inicial, as obras selecionadas passaram a ser analisadas para investigar se elas tratavam da inovação pedagógica. Identificamos 161 artigos que descreveram ou investigaram a inovação pedagógica no cotidiano da EFE. Nosso critério de análise foi interpretativo, com a leitura dos resumos e, quando necessário, do texto integral.

Estabelecemos como categorias de análise dos artigos: a classificação dos periódicos segundo o WebQualis da EF, a data do artigo, a região do país (do local onde foi produzido), o tipo de escola e o nível de ensino analisados no artigo, bem como o tipo de pesquisa e os temas tratados. Partindo desses critérios, elaboramos as seguintes questões norteadoras da análise: Quais as características dos estudos sobre inovação pedagógica publicados pela comunidade acadêmica da EF? Quais os ciclos de escolarização abordados com maior frequência? Como essas pesquisas se distribuem pelas diferentes regiões brasileiras? Quais são os diferentes tipos de pesquisas utilizados nesses estudos? Essas pesquisas foram realizadas em escolas públicas ou privadas?

Durante a leitura e análise dos resumos e artigos fomos definindo as categorias, de acordo com a similaridade temática apresentada. Assim, foram criadas oito categorias: temas da CCM; sistematização da EFE; estratégias de ensino na EFE; inclusão na EFE; recursos didáticos na EFE; interdisciplinaridade na EFE; conscientização corporal na EFE; e lazer na EFE. A definição dessas categorias foi realizada em três reuniões de consenso (GOMES; CAMINHA, 2014), com a participação de todos os autores, nas quais analisamos a coerência dessas categorias e a classificação dos artigos.

Na categoria Temas da CCM foram enquadrados os trabalhos que analisaram práticas pedagógicas inovadoras relacionadas com os elementos culturais jogo, esporte, luta, dança, ginástica e circo. Já os artigos classificados na categoria Sistematização da EFE analisaram como docentes de EF que ministram aulas inovadoras planejavam a sua ação didática na escola, principalmente sobre questões ligadas aos objetivos, conteúdos, método e avaliação. Alocamos nessa categoria estudos que não tratavam de uma manifestação da cultura corporal de movimento específica, mas sim de como o professor, que é autor da sua prática pedagógica, "pensa" o seu planejamento didático-metodológico (CAPARROZ; BRACHT, 2007).

Estratégias de Ensino na EFE foi a categoria que reuniu artigos sobre estratégias didáticas para os docentes de EF alcançarem seus objetivos educacionais. Nesses artigos são discutidas, por exemplo, as estratégias utilizadas na intervenção com turmas mistas durante as aulas de EF. Já na categoria Inclusão na EFE foram classificados os artigos que mostravam como os docentes de EF fazem para que todos os alunos participem de suas aulas, inclusive aquelas crianças e adolescentes que possuem alguma deficiência.

Materiais Curriculares na EFE foi a categoria que agrupou trabalhos que analisaram os instrumentos utilizados pelos professores nas aulas de EF para atingirem os seus objetivos educacionais e ensinar os conteúdos relacionados com as manifestações da CCM. Os Estudos 
que analisaram práticas pedagógicas interdisciplinares, que envolviam a EF e qualquer outro componente curricular da escola foram classificados na categoria Interdisciplinaridade na EFE.

Na categoria Conscientização Corporal na EFE classificamos os artigos nos quais foram apresentados professores de EF inovadores que trabalham com aspectos relacionados ao conhecimento sobre o corpo em suas aulas. Já os estudos que envolveram discussões e debates sobre o lazer nas aulas de EFE foram alocados na categoria Lazer na EFE.

\section{Resultados e Discussão}

Na Tabela 1, apresentamos o número de artigos sobre a inovação pedagógica no cotidiano da EFE de ambas as áreas, distribuídos pelos estratos do WebQualis da EF.

Tabela 1 - Distribuição de artigos encontrados e utilizados por estrato do WebQualis 2014

\begin{tabular}{cc}
\hline Qualis & Artigos de Inovação Pedagógica \\
\hline A1 & 0 \\
A2 & 17 \\
B1 & 28 \\
B2 & 32 \\
B3 & 10 \\
B4 & 05 \\
B5 & 69 \\
\hline Total & $\mathbf{1 6 1}$ \\
\hline
\end{tabular}

Fonte: Elaborado pelo autor, 2017.

Chama a atenção o elevado número de artigos encontrados nos periódicos classificados no estrato B5 do WebQualis. Dessa forma, é possível perceber que uma parte considerável da publicação tem sido desconsiderada nas pesquisas que analisaram a produção científica relacionada à EFE, já que tem predominado a análise de periódicos com melhor classificação no WebQualis, como aconteceu em Neira (2012) e Wiggers et al. (2015).

Gráfico 1 - Distribuição de artigos sobre a inovação pedagógica na EFE em diferentes décadas

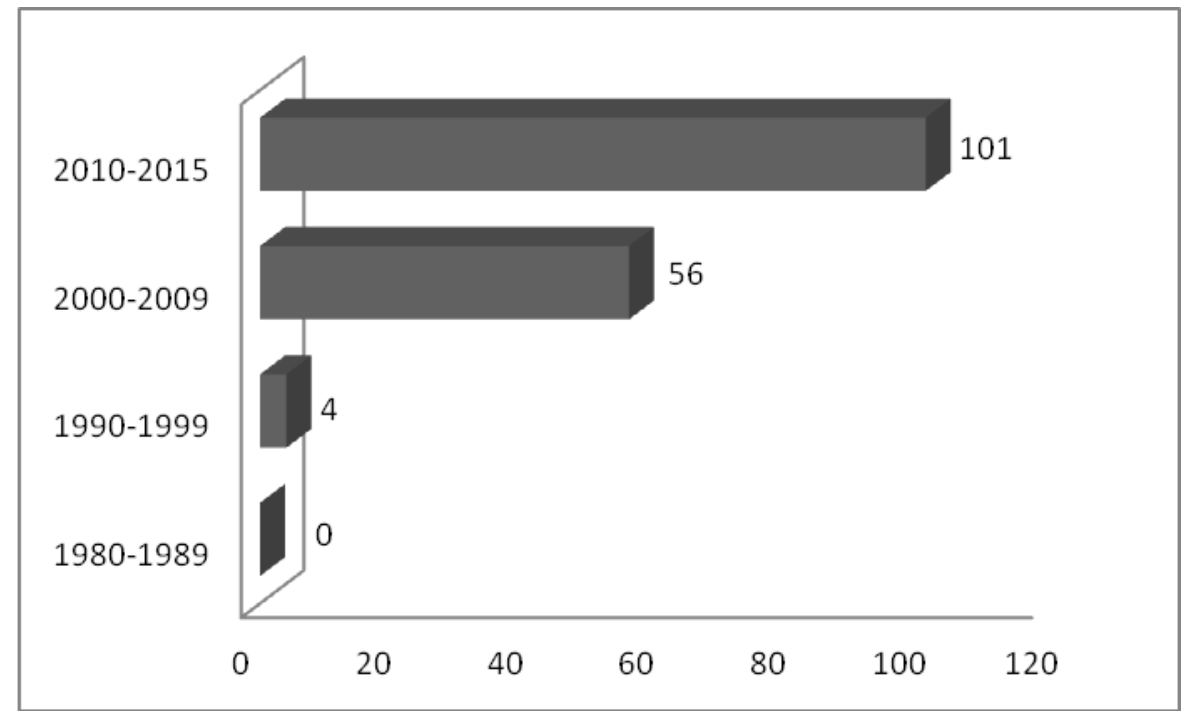

Fonte: Elaborado pelo autor, 2017. 
As pesquisas sobre práticas pedagógicas inovadoras nas aulas de EFE começaram a ocorrer na década de 1990. Nesse momento histórico, foram publicados 2,5\% dos estudos analisados. Na primeira década do século XXI encontramos 34,8\% dos estudos relacionados com essa temática. Por conseguinte, verificamos que a maior parte dos estudos $(62,7 \%)$ foi publicada no período entre 2010 e 2015, evidenciando o crescimento na publicação de trabalhos que descrevem ou investigam uma prática pedagógica que pode ser considerada inovadora, na perspectiva apresentada por Faria, Machado e Bracht (2012).

Gráfico 2 - Distribuição dos estudos sobre a inovação pedagógica na EFE por região brasileira

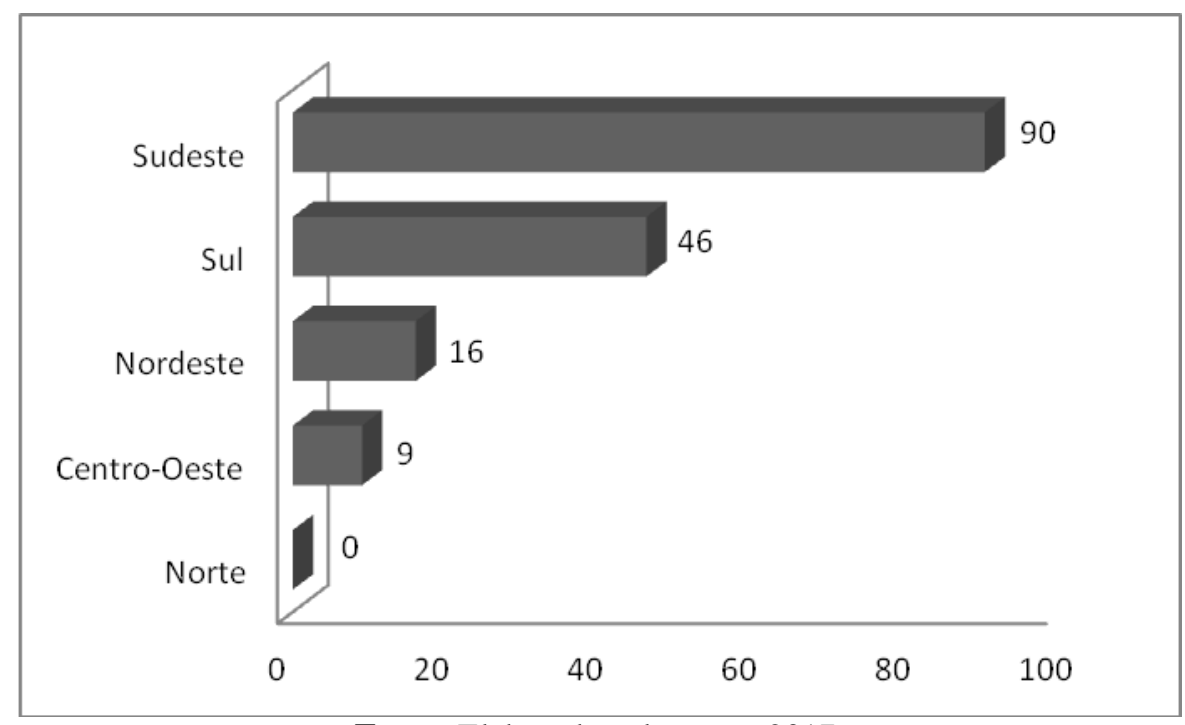

Fonte: Elaborado pelo autor, 2017.

A região Sudeste concentra a maior parte dos artigos analisados, compondo $56 \%$ da publicação científica sobre a temática aqui investigada. Logo em seguida aparecem estudos realizados na região Sul, com $28,5 \%$ das pesquisas; na região Nordeste, com $10 \%$ das publicações; e na região Centro-Oeste, com 5,5\%. Matos et al. (2013), Maldonado, Silva e Miranda (2014) e Wiggers et al. (2015) também encontraram resultados semelhantes em seus estudos de produção do conhecimento sobre EFE, apontando que as regiões Sudeste e Sul produzem mais publicações sobre as temáticas relacionadas com a EFE.

Maldonado, Silva e Miranda (2014) mencionam que esta realidade pode estar relacionada com a instalação dos principais programas de Pós-Graduação Stricto Sensu nas regiões Sul e Sudeste. Além disso, os autores argumentam que os periódicos relevantes, que publicam estudos relacionados com a EFE, são coordenados por pesquisadores que atuam nessas regiões. 
Gráfico 3 - Artigos de inovação pedagógica divididos em escolas públicas e privadas

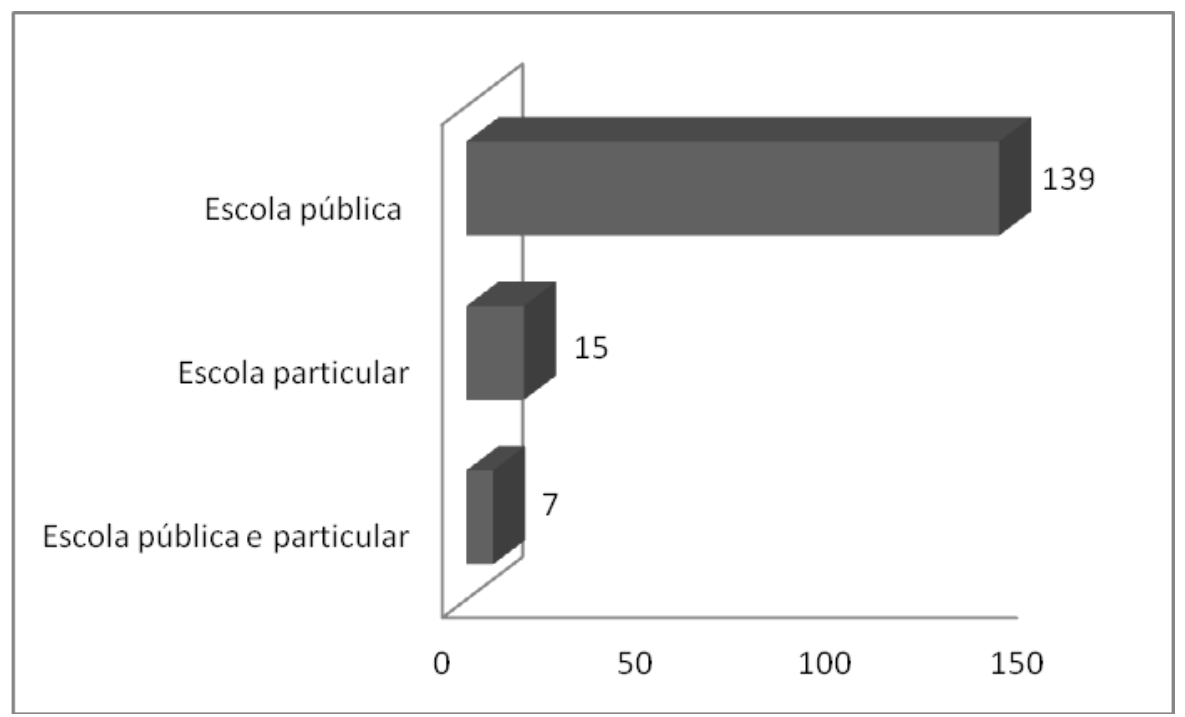

Fonte: Elaborado pelo autor, 2017.

Os artigos identificados apresentam pesquisas ou relatam experiências que ocorreram em escolas públicas, compondo $86,4 \%$ dos estudos analisados. Apenas 9,3\% dessas investigações foram realizadas em escolas da rede privada e $4,3 \%$ foram produzidos nas duas redes de ensino ao mesmo tempo.

Gráfico 4 - Ciclos de escolarização estudados em pesquisas sobre a inovação pedagógica na EFE

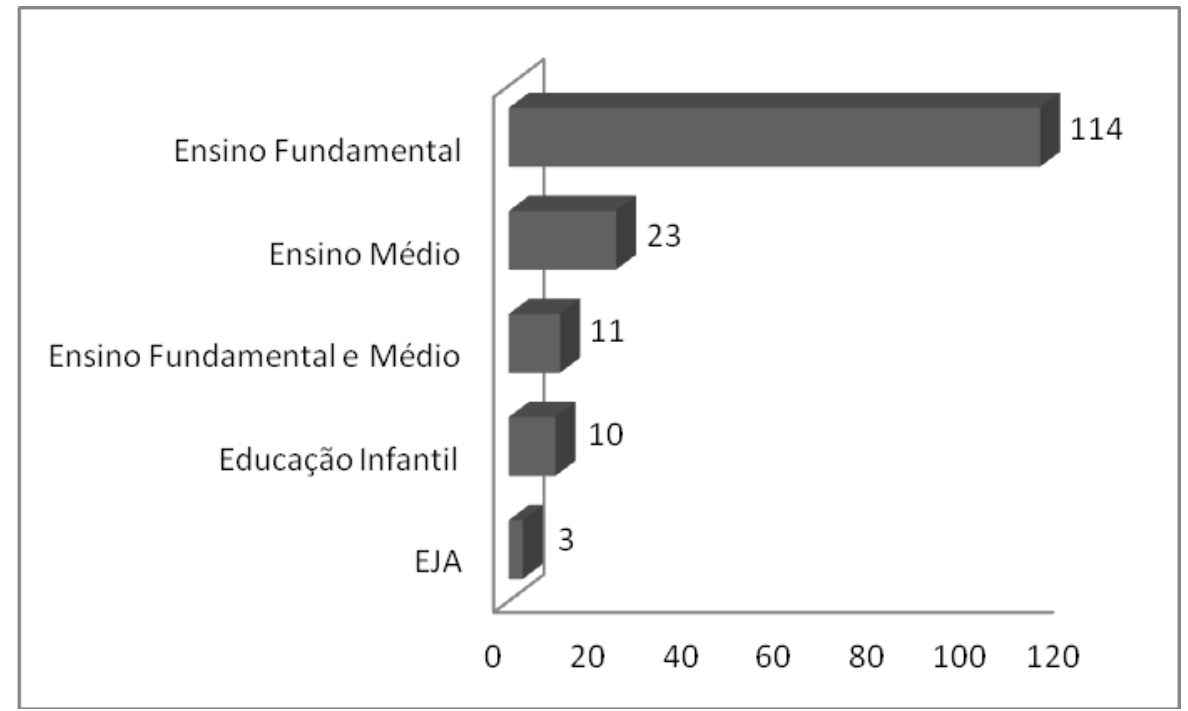

Fonte: Elaborado pelo autor, 2017.

Ao analisar os ciclos de escolarização investigados nos artigos encontrados, verificamos que o Ensino Fundamental foi o ciclo escolhido por 70,8\% das publicações. Logo após, apareceram os estudos realizados no Ensino Médio, com 14,2\% das publicações, seguidos por trabalhos que analisaram o Ensino Fundamental e Médio ao mesmo tempo, com 6,8\%. Como já imaginávamos, os estudos sobre Educação Infantil e sobre a Educação de Jovens e Adultos, aparecem com menor frequência. Resultados semelhantes foram 
apresentados por Betti, Ferraz e Dantas (2011) e Maldonado, Silva e Miranda (2014). Acreditamos que o predomínio de estudos no Ensino Fundamental seja consequência de sua maior duração, já que os estudantes permanecem neste ciclo da educação básica por nove anos, no mínimo. É possível, ainda, que a maior predisposição de crianças e adolescentes para participar das aulas de EF (BETTI; LIZ, 2003, FILGUEIRAS et al., 2007) também influencie a maior produção científica com crianças e adolescentes do Ensino Fundamental (MALDONADO et al., 2017). Entretanto, esta realidade não minimiza a importância de compreender com maior ênfase sobre a inovação pedagógica nas aulas de EF nos outros ciclos.

Gráfico 5 - Tipos de pesquisa dos estudos sobre a inovação pedagógica na EFE

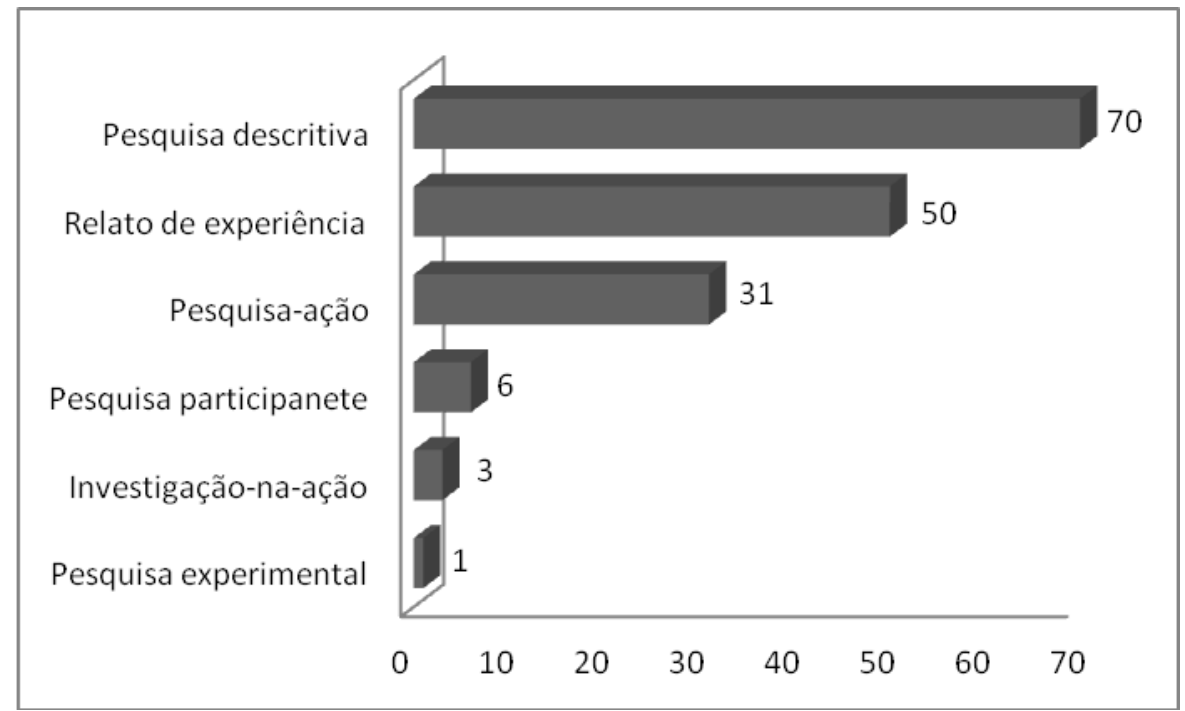

Fonte: Elaborado pelo autor, 2017.

A maior parte dos artigos analisados apresenta pesquisas descritivas, representando $43 \%$ dos estudos nos quais a inovação pedagógica foi identificada. A preponderância desse tipo de pesquisa já foi apontada por Bracht et al. (2012). A inovação pedagógica foi exposta também em relatos de experiência $(31 \%)$ e em estudos que apresentam uma pesquisa-ação (19\%). A pesquisa participante $(3,7 \%)$, a investigação-na-ação $(1,9 \%)$ e a pesquisa experimental $(0,6 \%)$ apareceram em menor frequência nos artigos encontrados.

Notamos que há um número elevado de relatos de experiência e ponderamos que, talvez, este tipo de publicação seja o que mais permite ao professor que trabalha com EF na escola compartilhar sua própria produção de conhecimento. Entretanto, geralmente, esse tipo de publicação é desvalorizado diante da lógica de uma avaliação bibliométrica.

Também é importante ressaltar que quase a totalidade dos estudos em que os professores relatam as suas experiências pedagógicas nas aulas de EF estão publicados em periódicos com estratos B4 ou B5 no WebQualis da EF. Essa informação é de extrema importância para os pesquisadores que querem compreender melhor sobre esse fenômeno, já que esses periódicos muitas vezes não são considerados relevantes, por conta dos critérios de qualidade estabelecidos pela CAPES (BRACHT, 2015).

\section{Categorias mais estudadas nos artigos de Inovação Pedagógica}

No Gráfico 6, ilustramos os principais temas problematizados nos estudos sobre inovação pedagógica classificados nas categorias adotadas em nossa pesquisa. 
Gráfico 6 - Categorias relacionadas com a inovação pedagógica na EFE

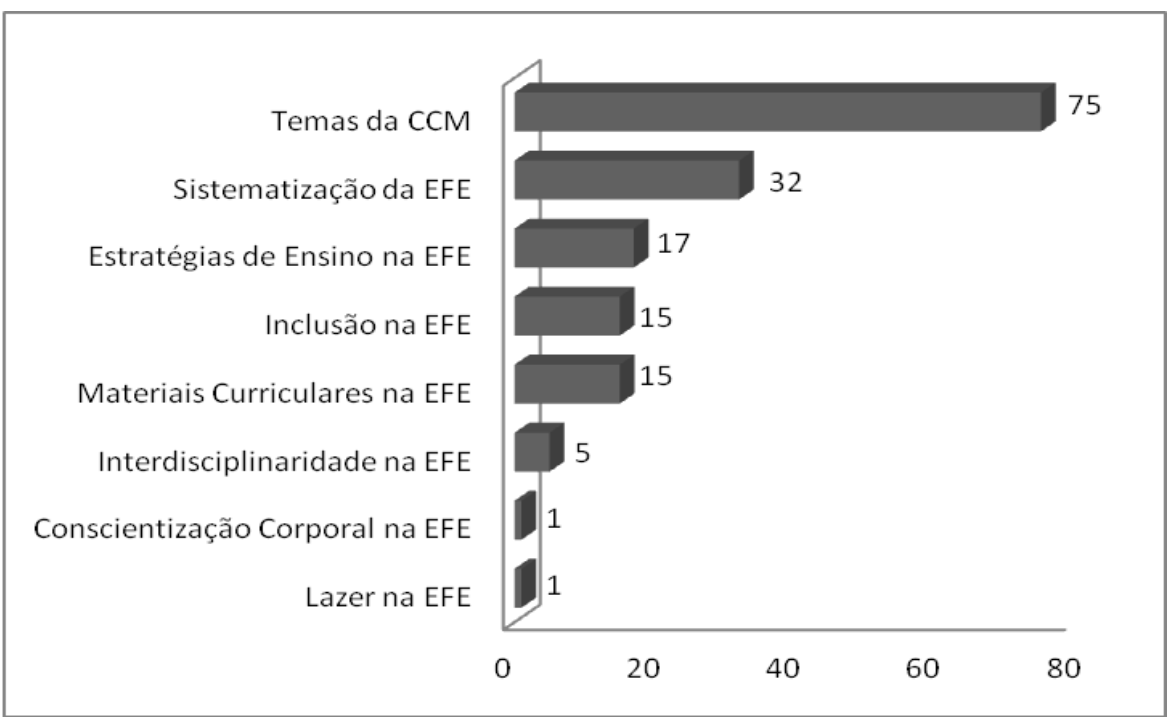

Fonte: Elaborado pelo autor, 2017.

A análise dessa distribuição temática mostrou que a maioria dos artigos avaliados descreve ou investiga a inovação relacionada com os temas da CCM. Nesses artigos, que representam $46,4 \%$ de toda a produção científica analisada, identificamos práticas pedagógicas de professores que ensinaram diferentes elementos culturais, como: jogo, esporte, dança, luta, ginástica e circo. Para compreender com maior profundidade o número de artigos que foram encontrados em cada uma das manifestações da CCM tematizadas, apresentamos o Gráfico 7.

Gráfico 7 - Manifestações da CCM ensinadas

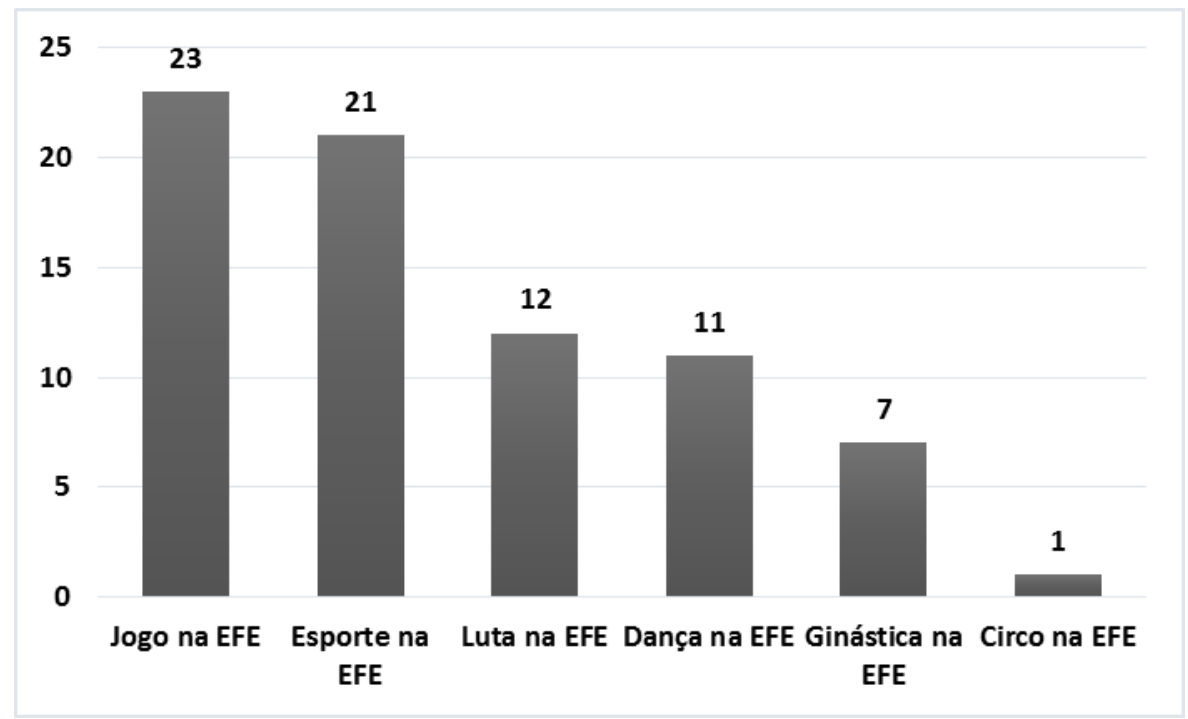

Fonte: Elaborado pelo autor, 2017.

O jogo foi a manifestação da CCM mais presente nas aulas de EFE descritas ou investigadas, representando 30,5\% dos artigos publicados nessa categoria. Em seguida, aparecem o esporte $(28 \%)$, a luta (16\%), a dança $(14,5 \%)$, a ginástica $(9,5 \%)$ e o circo $(1,5 \%)$. Especificamente sobre o ensino do jogo na EFE, identificamos a tematização de jogos eletrônicos, jogos cooperativos, jogos indígenas, jogos da cultura popular de diferentes países, além do 
uso do jogo como estratégia para estimular diferentes aprendizagens e do envolvimento dos estudantes na construção de jogos.

Os estudos encontrados acerca da tematização do esporte nas aulas de EF discutiram sobre esporte de orientação, rúgbi, modalidades esportivas com raquetes, pesca esportiva, modalidades esportivas com rodas, vôlei sentado, esporte de aventura, atletismo, futebol de seis quadrados e modalidades esportivas coletivas. Essas pesquisas também mostraram professores que procuram estimular o pensamento crítico dos estudantes ou que adotam como pressupostos determinada proposta pedagógica, como a concepção de aulas abertas, a proposta crítico-emancipatória, ou as teorias pós-críticas de educação. Identificamos, ainda, estudos nos quais as três dimensões dos conteúdos aparecem relacionadas ao ensino do esporte.

As lutas ensinadas nas aulas de EF, que foram descritas ou investigadas na publicação analisada, foram: capoeira, muay thai, caratê, qigong, judô, sumô e esgrima. As práticas pedagógicas apresentadas nesses artigos se pautaram nas três dimensões dos conteúdos e inteligências múltiplas. Também foi discutido como ensinar lutas por meio de jogos e como trabalhar a diferença entre o aprendizado de uma arte marcial e a utilização desse conhecimento para brigar com outras pessoas.

O ensino da dança na EFE, identificado nos artigos analisados, trouxe como temas: dança de salão, hip hop, samba, danças folclóricas, chula, carimbó, frevo e funk. Para elaborar e viabilizar essas aulas, os docentes de EF se pautaram nas três dimensões dos conteúdos, na perspectiva histórico-crítica e nas teorias pós-críticas de Educação. Em alguns artigos identificamos o envolvimento dos discentes na discussão sobre relações de gênero na dança, além do estímulo à criatividade para a realização de coreografias.

Diferentes modalidades da ginástica foram tematizadas nas práticas pedagógicas expressas nos artigos analisados, como a ginástica rítmica, a artística, a acrobática, a de academia e a geral. Para isso, foram utilizadas como referência a proposta crítico-emancipatória, a concepção de aulas abertas, as três dimensões dos conteúdos e a formação do pensamento crítico dos estudantes sobre essas manifestações da CCM. Encontramos apenas um estudo que apresentou o trabalho com circo nas aulas de EF. Este estudo se fundamenta na perspectiva histórico-crítica como referência para tematizar esta prática corporal.

Matos et al. (2013) analisaram a produção acadêmica sobre os conteúdos de ensino na EFE, em 14 periódicos da área. Os resultados deste estudo também demonstraram que a tematização de diferentes manifestações da CCM tem sido mais frequente. As modalidades esportivas encontradas nessa pesquisa foram: futebol, handebol, atletismo, natação, tênis e esporte adaptado. As danças foram: dança de rua, dança popular, dança folclórica, dançaimprovisação e dança de salão. Os jogos e brincadeiras foram: brincadeiras açorianas, jogos populares, jogos eletrônicos, xadrez, jogos cooperativos e brincadeiras folclóricas. As ginásticas foram: geral, acrobática, circense, artística e rítmica. Entre as lutas, apenas o judô foi identificado.

Tendo como foco a forma como o atletismo tem sido abordado nas aulas de EF, Silva et al. (2015) realizaram um levantamento de artigos publicados em 15 periódicos científicos da área. Os autores constataram haver um crescimento na presença do atletismo nos programas de EF na escola. Aparentemente, podemos inferir que há professores que inovam e que não limitam suas aulas à reprodução de técnicas esportivas das quatro modalidades que se tornaram predominantes na EFE. A importância desta diversificação dos temas apresentados nas aulas tem sido destacada por vários autores, como Darido (2004). Concordando com Fensterseifer e Silva (2011), entendemos que a apresentação de conhecimentos de diferentes manifestações da CCM, é uma forma de trazer o novo para as aulas de EF.

A categoria sistematização da EFE aparece em seguida, com 19,5\% da produção científica sobre inovação pedagógica. Os estudos que foram classificados nessa categoria mostraram práticas pedagógicas dos docentes de EF que construíram uma forma de organizar o cur- 
rículo em sua escola, sendo esta outra ação considerada inovadora, na perspectiva defendida por Fensterseifer e Silva (2011).

$\mathrm{Na}$ terceira categoria, reunimos os artigos que descrevem ou investigam as estratégias de ensino utilizadas pelos docentes de EF na escola, representada por 10,5\% do total de trabalhos analisados. Identificamos que diferentes estratégias aparecem nos relatos ou pesquisas selecionadas, como o envolvimento conjunto de meninos e meninas nas atividades, o estimular à participação dos alunos nas aulas, o ensino com enfoque nas três dimensões do conteúdo, a implementação do planejamento participativo e o estímulo à autonomia dos estudantes.

Artigos que apresentam a inovação na seleção de materiais curriculares utilizados em aulas de EF representaram 9,5\% do total de trabalhos analisados. Os recursos utilizados por esses docentes nas aulas foram: blog, filmes, notícias publicadas em jornais, matérias elaboradas pela televisão, desenho animado, livros didáticos e paradidáticos, charges, tirinhas, história em quadrinhos, textos acadêmicos, poema, poesia, crônicas, textos elaborados pelos alunos, textos elaborados pelos docentes, materiais audiovisuais e paródias de músicas. Nesta categoria também foram encontrados artigos que discutiam sobre a mídia-educação como forma de ensinar conteúdos pertinentes às práticas corporais nas aulas de EF.

A utilização de estratégias de ensino e recursos didáticos diferenciados evidencia que uma parcela dos professores, apresentados nos artigos analisados, constrói formas de estimular uma aprendizagem significativa durante suas aulas, a partir do envolvimento dos estudantes no processo de aprendizagem. Para Silva e Bracht (2012), ao atuar desta forma, esses professores demonstram não mais limitar suas aulas à reprodução de gestos de um restrito número de modalidades esportivas.

Estudos que apresentaram práticas pedagógicas inclusivas nas aulas de EF somaram 9,5\% da produção científica analisada. Esses trabalhos mostraram como os docentes de EF implementam a inclusão de discentes com asma, deficiência física, intelectual e visual nas suas aulas. Além disso, também compreenderam como os alunos que não apresentam deficiências avaliam a participação das crianças com alguma limitação nas aulas de EF na escola.

A categoria interdisciplinaridade na EFE foi constituída por 3\% dos artigos analisados, nos quais foram apresentados trabalhos interdisciplinares envolvendo conteúdos da $\mathrm{EF}$, de Ciências e de Artes. Os projetos mencionados estimularam reflexões sobre educação ambiental, expressão gráfica, desenhos, pinturas e modelagens com jogos e brincadeiras. Já os trabalhos inovadores desenvolvidos sobre conscientização corporal e sobre lazer apareceram em $0,5 \%$ da produção científica.

Ao analisar os artigos que investigaram a produção do conhecimento sobre a EFE, também constatamos que questões de ordem didática estão sendo cada vez mais estudadas pelos pesquisadores da EF. Betti, Ferraz e Dantas (2011), por exemplo, realizaram um estudo sobre o estado da arte na EFE. Os autores analisaram publicações de 11 periódicos da área de EF. Com os resultados dessa revisão sistemática, foi possível perceber o crescimento no número de estudos que buscaram analisar questões didáticas, subsidiando a prática pedagógica dos docentes. Portanto, pode ser notada uma preocupação maior dos pesquisadores com o campo da didática e, por consequência, com a identificação de novas formas de ensinar.

Neira (2012) analisou as principais contribuições da produção acadêmica brasileira sobre a docência em EF em dois periódicos da área (Motriz e Movimento). Os resultados desse estudo também possibilitaram a identificação de diferentes contribuições para a melhora da prática pedagógica em EF. Maldonado et al. (2014), por sua vez, ao realizarem um estudo de revisão, realizado em sete periódicos da área de EF, mostraram que os docentes desse componente curricular estão ensinando diversos conteúdos de ordem conceitual e atitudinal em suas aulas, demonstrando uma clara inovação didático-pedagógica desses professores, principalmente porque eles romperam com uma didática pautada somente nos conteúdos de ordem 
procedimental e passaram a planejar as suas aulas pensando na formação integral dos estudantes.

Bracht et al. (2011) mapearam a produção do conhecimento sobre o tema da EFE nas décadas de 1980-2010 em nove periódicos científicos da área. Os autores verificaram o predomínio de pesquisas que apresentaram o diagnóstico das aulas de EF. Entretanto, pesquisas que focalizaram a intervenção, relacionadas diretamente com as ações pedagógicas propriamente ditas e, por consequência, com as práticas pedagógicas inovadoras, já representavam $34,8 \%$ da produção científica publicada por esses periódicos.

Resultados semelhantes foram obtidos por Wiggers et al. (2015), que analisaram as tendências da pesquisa em EFE no Brasil em oito periódicos da área. Com os resultados desta revisão sistemática verifica-se que, como identificado por Bracht (2011), ainda existe uma tendência desses estudos focalizarem a realização de diagnóstico sobre o que acontece nas aulas. Todavia, nos últimos anos vem aumentando, de forma significativa, o número de artigos que analisaram a prática pedagógica na EFE, dando enfoque para questões como: métodos de ensino, avaliação, currículo/organização, conteúdos, trato didático-pedagógico, formação, intervenção e cultura escolar.

Assim sendo, tanto os resultados desse estudo quanto a produção científica mais recente da área, demonstram que uma parcela dos docentes que lecionam nas escolas brasileiras está produzindo práticas pedagógicas com características inovadoras em diferentes unidades escolares espalhadas pelo Brasil, principalmente, porque diversificam as manifestações da CCM tematizadas nas aulas, sistematizam o seu próprio currículo na escola, utilizam diversificadas estratégias de ensino, procuram incluir todos os estudantes nas atividades propostas, se preocupam em utilizar diferentes materiais curriculares para facilitar a aprendizagem dos estudantes, organizam situações didáticas interdisciplinares e/ou desenvolvem conteúdos relacionados com a consciência corporal e com o lazer nas aulas de EFE.

\section{Considerações Finais}

Consideramos que a produção de conhecimento sobre as práticas pedagógicas inovadoras na EFE aumentou desde a década de 1990, sobretudo a partir do início deste século e, principalmente, nesta década. Contudo, isto não significa necessariamente que a inovação pedagógica tenha sido ampliada nas aulas de EF, mas que há indícios nesse sentido, já que a publicação com foco na temática da inovação tornou-se mais visível.

Salientamos, além disso, que há dois aspectos cruciais para compreender qualitativamente o aumento da produção acadêmica identificado por nós:

(1) a busca em periódicos da EF e da Educação classificados em estratos mais baixos do WebQualis, ou seja, adentrar pela contramão do que tem sido valorizado formalmente como produção "qualificada" do conhecimento na EFE. Entendemos que esses estudos são extremamente relevantes, pois eles podem ser realizados por professores que, muitas vezes, não estão acostumados à escrita acadêmica, mas que, ainda assim, apresentam conhecimentos construídos no contexto escolar, diminuindo o hiato entre o que se produz na Universidade e a realidade do cotidiano escolar;

(2) a valorização da escola pública brasileira como espaço-tempo formativo-criativo inovador do trabalho colaborativo entre professores, professoras, alunos e alunas, isto é, enfatizar a complexidade e as contradições da escolarização no país a partir da EFE e desmistificar a previsível imutabilidade da crença de que a escola pública seja precária. Acreditamos no contrário e defendemos a excelência na qualidade da Educação Básica (e Superior) pública.

Sugerimos que, para fundamentar esse caminho de modo mais sólido, outros estudos sejam realizados acerca dos meandros levantados nesta pesquisa. Sem esgotar as inúmeras possibilidades de investigar a temática, vislumbramos a realização de pesquisas futuras sobre 
as características da inovação pedagógica em cada ciclo de escolarização e em diferentes regiões brasileiras. Além disso, identificamos a necessidade de compreender como os professores têm tematizado as diversas manifestações da CCM em suas aulas. Embora a diversificação das temáticas seja essencial para que os estudantes possam compreender como esta cultura está presente em sua realidade, esta compreensão depende da forma como as aulas são conduzidas.

\title{
INNOVATION IN SCHOOL PHYSICAL EDUCATION: CHALLENGING PRE- DICTABLE IMMUTABILITY EDUCATIONAL AND PEDAGOGICAL
}

\begin{abstract}
In order to understand the characteristics of innovative pedagogical practices, we analyzed the scientific papers about innovation in the daily school of Physical Education, published in the journals from stratum A1 to B5 of WebQualis 2014. We identified 161 papers that analyzed pedagogical innovation, and a relevant part of this production is published in journals classified in stratum B4 and B5. The diversification of the themes presented, the systematization of the curriculum and the selection of various teaching strategies were the main forms of innovation identified. We conclude that there is an increase in the number of publications that evidences the existence of pedagogical practices that break with the tradition that has marked the Physical Education.
\end{abstract}

Keywords: Physical Education. School. Pedagogical innovation. Every-day school.

\section{INNOVACIÓN EN LA EDUCACIÓN FÍSICA EN LA ESCUELA: DESAFIANDO LA PREDECIBLE INMUTABILIDAD DIDÁCTICO-PEDAGÓGICA}

\section{Resumen}

Con el objetivo de comprender las características de las prácticas pedagógicas innovadoras, evaluamos los artículos científicos sobre innovación de la Educación Física (EF) en la escuela, publicados en periódicos de los estratos A1 a B5 del WebQualis 2014. Identificamos 161 artículos, siendo que una relevante parte de esta producción es divulgada en periódicos situados en revistas clasificadas en los estratos B4 y B5. La diversificación de las temáticas presentadas, la sistematización del currículo y la selección de variadas estrategias de enseñanza fueron las principales formas de innovación identificadas. Concluimos que hay un crecimiento en el número de publicaciones que evidencian la existencia de prácticas pedagógicas que rompen con la tradición que ha marcado la EF.

Palabras clave: Educación Física. Escuela. Innovación pedagógica. Vida cotidiana.

\section{Referências}

BETTI, M. O que se ensina e o que pode ser ensinado. A pedagogização dos conteúdos da Educação Física: tradição e renovação. Salto para o futuro - Educação Física Escolar: dilemas e práticas, v. 21, n. 11, p. 21-28, 2011.

BETTI, M.; FERRAZ, O. L.; DANTAS, L. E. P. T. Educação Física Escolar: estado da arte e direção futuras. Revista Brasileira de Educação Física e Esporte. São Paulo, v. 25, n. especial, p. 105-115, 2011. 
BETTI, M.; LIZ, M. T. F. Educação Física Escolar: a perspectiva de alunas do ensino fundamental. Motriz. Rio Claro, v. 9, n. 3, p. 135-142, 2003.

BRACHT, V. Dilemas no cotidiano da Educação Física Escolar: entre o desinvestimento e a inovação pedagógica. Salto para o futuro - Educação Física Escolar: dilemas e práticas, v. 21, n. 11, p. 14-20, 2011.

Educação Física, método científico e reificação. In: BRACHT, V.; STIGGER, M. P. Educação Física + Humanas. Campinas, SP: Autores Associados, 2015. p. 1-22.

BRACHT, V. et al. A Educação Física Escolar como tema da produção do conhecimento dos periódicos da área no Brasil (1980-2010): parte I. Movimento. Porto Alegre, v. 17, n. 2, p. 11-34, 2011.

BRACHT, V. et al. A Educação Física Escolar como tema da produção do conhecimento dos periódicos da área no Brasil (1980-2010): parte II. Movimento. Porto Alegre, v. 18, n. 2, p. 11-37, 2012.

CAPARROZ, F. E.; BRACHT, V. O tempo e o lugar de uma didática na Educação Física. Revista Brasileira de Ciências do Esporte. Campinas, v. 28, n. 2, p. 21-37, 2007.

CORREIA, W. R. Educação Física Escolar: desafiando a sua presumível imutabilidade. Revista Brasileira de Educação Física e Esporte. São Paulo, v. 28, n. 4, p. 691-700, 2014.

DARIDO, S. C. A educação física na escola e o processo de formação dos não praticantes de atividade física. Revista Brasileira de Educação Física e Esporte, v. 18, n. 1, p. 61-80, 2004.

FARIA, B. A.; MACHADO, T. S.; BRACHT, V. A inovação e o desinvestimento pedagógico na Educação Física Escolar: uma leitura a partir da teoria do reconhecimento social. Motriz. Rio Claro-SP, v. 18, n. 1, p. 120-129, 2012.

FENSTERSEIFER, P. E.; SILVA, M. A. Ensaiando o "novo" em Educação Física Escolar: a perspectiva de seus autores. Revista Brasileira de Ciências do Esporte. Florianópolis, v. 33, n. 1, p. 119-143, 2011.

FILGUEIRAS, I. P. et al. Concepções e preferências sobre as aulas de Educação Física Escolar: uma análise da perspectiva discente. Revista Mackenzie de Educação Física e Esporte. São Paulo, v. 6, n. 3, p. 23-31, 2007.

GOMES, I. S.; CAMINHA, I. O. Guia para estudos de revisão sistemática: uma opção metodológica para as Ciências do Movimento Humano. Movimento. Porto Alegre, v. 20, n. 1, p. 395-411, 2014.

MALDONADO, D. T.; SILVA, S. A. P. S; MIRANDA, M. L. J. M. Pesquisas sobre Educação Física no cotidiano da escola: o estado da arte. Movimento. Porto Alegre, v. 20, n. 4, p. 1373-1395, 2014.

MALDONADO, D. T. et al. As dimensões conceituais e atitudinais dos conteúdos na Educação Física Escolar. Pensar a Prática. Goiânia, v. 17, n. 1, p. 546-559, 2014. 
MALDONADO, D. T. et al. Perspectivas de mudança nas práticas pedagógicas da educação física escolar: uma análise dos estudos publicados nos anais de eventos paulistas. Conexões: Educação Física, Esporte e Saúde. Campinas-SP, v. 15, n. 3, p. 349-367, 2017.

MATOS, J. C. et al. A produção acadêmica sobre os conteúdos de ensino na Educação Física Escolar. Movimento. Porto Alegre, v. 19, n. 2, p. 123-148, 2013.

NEIRA, M. G. Alternativas existem! Análise da produção científica em dois periódicos brasileiros sobre a docência na Educação Física. Movimento. Porto Alegre, v. 18, n. 1, p. 241-257, 2012.

NEIRA, M. G. Ensino da Educação Física. São Paulo: Cengage Learning, 2010. (Coleção Ideias em Ação).

ROMANOWSKY, J. P.; ENS, R. T. As pesquisas denominadas do tipo "estado da arte" em educação. Diálogo Educacional. Curitiba, v. 6, n. 19, p. 37-50, 2006.

SILVA, M. S.; BRACHT, V. Na pista de práticas e professores inovadores na Educação Física Escolar. Kinesis, v. 30, n. 1, p. 80-94, 2012.

SILVA, E. V. M. et al. Atletismo (ainda) não se aprende na escola? Revisitando artigos publicados em periódicos científicos da Educação Física nos últimos anos. Movimento. v. 21, n. 4, p. 1111-1122, 2015.

WIGGERS, I. D. et al. Um "raio x" da produção do conhecimento sobre Educação Física Escolar: análise dos periódicos de 2006-2012. Movimento. Porto Alegre, v. 21, n. 3, p. 831845, 2015.

Recebido em: 07/02/2017

Revisado em: 25/01/2018

Aprovado em: 25/01/2018

Endereço para correspondência:

danieltmaldonado@yahoo.com.br

Daniel Teixeira Maldonado

Instituto Federal de Educação, Ciência e Tecnologia de São Paulo

Pedro Vicente, 625

Canindé - São Paulo - SP - Brasil

CEP: 01109-010 